\title{
Analisis Persepsi Pengunjung Terhadap Ketersediaan Produk Wisata Di Pantai Sauwmyen Distrik Oransbari Kabupaten Manokwari Selatan
}

\author{
Bartolomeus Kawey ${ }^{1}$, Rumas Alma Yaap², Naftali Mansim ${ }^{3}$ \\ 1, Alumni Jurusan Ekonomi Pembangunan, Universitas Papua \\ ${ }^{2,3}$ Dosen Jurusan Ekonomi Pembangunan, Universitas Papua
}

Received: Maret 2021; Accepted: Maret 2021; Published: Maret 2021

\begin{abstract}
Abstrak
Produk wisata adalah bahagian penting dalam pengembangan sektor pariwisata. Kondisi riil produk wisata dalam bentuk atraksi wisata, eksebilitas, fasilitas, di lokasi objek wisata Pantai Sauwyen tidak terlalu mendudukung untuk aktivitas pengunjung wisata. Kondisi ini tentunya akan sangat berpengruh pada pengalaman dan kenyamanan berwisata. Penelitian ini bertujuan untuk mengetahui Persepsi wisatawan tentang Kondisi produk wisata serta kenyaman pengunjung wisata yang didapatkan selama berwisata ke Pantai Sauwmyen Distrik Oransbari Kabupaten Manokwari Selatan. Metode analisis yang duganakan adalah Deskriptif dimana data yang telah terkumpul selanjutnya dianalisis secara kuantitatif dan kualitatif. Untuk menjawab pertanyaan penelitian yang pertama maka digunakan teknik analisis distribusi frekwensi terhadap persepsi responden dengan Skala Likert, teknik teknik analisis Customer Satisfaction Index (CSI) untuk menilai kenyamanan atau nilai emenities yang didapatkan oleh pengunjung wisata. Serta pendekatan IPA (Importand Performance Analissys) dengan penentuan untuk melihat persepsi responden terhadap masing-masing indikator produk wisata serta penetuan strategi pengembangan objek wisata Pantai Sauwyen. Hasil penelitian menunjukan bahwa ketersediaan produk wisata dalam bentuk atraksi wisata, eksebitas, dan fasilitas yang memadai tidak sepenuhnya didapati di lokasi objek wisata, oleh karena itu hasil analisis data menujukan persepsi responden terhadap produk wisata pada objek wisata adalah Kurang Puas. Selanjutnya sesuai realita maka kenyamanan pengunjung wisata selama berada di lokasi wisata ada pada kualifikasi Kurang Puas. Maka strateginya adalah Perlu adanya pengembangan objek wisata Pantai Sauwyen oleh warga setempat dan pemerintah untuk meningkatkan kinerja, indikator produk wisata yang mempunyai kebutuhan utama bagi para pengunjung dan dapat dilihat pada responden dari setiap individu secara kepentingan maupun kinerja untuk pengembangan objek wisata pantai Sauwmyen yang lebih baik kedepan untuk digunakan oleh seluruh wisatawan
\end{abstract}

Kata kunci: persepsi, kepuasan, produk wisata

\begin{abstract}
Tourism products are an important part of the development of tourism sector. the real conditions of tourism products in the form of tourist attractions, facilities, at the location of the tourism attraction at the Sauwmyen beach re not very supportive for tourist activity. this condition will certainly greatly affect the experience and comfort travel. This study aims to determine the perceptions of tourists about the condition of tourism products and the comfort of tourist visitors obtained during a trip to Sauwmyen Beach, Oransbari district, South Manokwari Regency. Method the analysis used is descriptive where the data that has been collected is then analyzed quantitatively and qualitatively. To answer the first research question, the frequency distribution analysis technique is used perceptions of respondents with a Likert scale, analysis techniques Customer Satisfaction Index (CSI) to assess the comfort or emotional value obtained by tourist visitors. As well as the IPA (Import and Performance Analysis) approach with determination to see the respondents' perceptions of each tourism product indicator as well as determining the strategy for developing a tourist attraction in the coast of Sauwmyen. The result showed that the availability of tourism product in the form of tourism attraction excitability and adequate facilities are not fully found at the location of tourist object, there for their result of data analysis show that respondents' perceptions of tourism product at tourist object are less satisfied. Then according to reality then the
\end{abstract}


comfort of tourist visitors while in tourist sites is less satisfied. Then the strategy is the need for the development of sauwmyen beach tourism object by local residents and the government to improve performance, indicator tourism product that have a primary need for visitors and can be seen in the respondents of each individual in terms of their interest and performance for the development of a better Sauwmyen beach tourism object in the future to be used by all tourists.

Keywords: perception, satifaction, tourism products

How to Cite: Kawey, B., Yap, Rumas A., Mansim, N. (2021). Analisis Persepsi Pengunjung Terhadap Ketersediaan Produk Wisata Di Pantai Sauwmyen Distrik Oransbari Kabupaten Manokwari Selatan. JFRES: Journal of Fiscal and Regional Economy Studies, 4(1), 37 - 49.

\footnotetext{
$\bowtie$ Corresponding author:

E-mail: r.yap@unipa.ac.id
}

\section{PENDAHULUAN}

Sejak merosotnya harga minyak bumi dipasar internasional pada awal tahun 80-an terjadi krisis perekonomian dunia yang berkepanjangan, pertumbuhan ekonomi dunia mengalami perlambatan karena ketergantungan akan sektor migas terhadap perekonomiannya. Kemorosotan ini menyebabkan banyak negara kemudian mengambil kebijakan untuk mengembangkan sektor-sektor ekonomi lainya untuk menunjang perekonomian dan salah satu sektor yang paling berpotensi adalah sektor pariwisata.

Menyadari akan penting dan berpotensinya sektor pariwisata maka pemerintah Indonesia dalam beberapa dasa warsa terakhir menjadikan sektor pariwisata sebagai lokomotif baru perekonomian dan terus menggalakan pembangunan sektor pariwisata dan itu menunjukan kontribusi positif terehadap pereknomian Indonesia. Devisa dari sektor pariwisata pada tutup buku 2018 meningkat mencapai angka US $\$ 19,29$ miliar atau hampir menembus target tahun tersebut sebesar US\$20 miliar. Kontribusi sektor pariwisata terhadap Produk Demestik Bruto tahun 2018 mencapai 4,50\%, dan tahun 2019 mencapai 4,80\% (warta ekonomi.co.id).

Tujuan pengembangan pariwisata, bukan hanya sekedar untuk meningkatkan perolehan devisa bagi negara, akan tetapi lebih jauh diharapkan pariwisata dapat berperan sebagai katalisator pembangunan (agent of development). Dilihat dari sudut ekonomi, sedikitnya ada delapan keuntungan pengembangan pariwisata di Indonesia: Pertama, peningkatan kesempatan berusaha. Kedua, kesempatan kerja. Ketiga, peningkatan penerimaan pajak. Keempat, peningkatan pendapatan nasional. Kelima, percepatan proses pemerataan pendapatan. Keenam, meningkatkan nilai tambah produk hasil kebudayaan. Ketujuh, memperluas pasar produk dalam negeri. Dan kedelapan, memberikan dampak multiplier efect dalam perekonomian sebagai akibat pengeluaran wisatawan, para investor, maupun perdagangan luar negeri.

Sugiarto (2019) mengatakan bahwa "dijadikannya pariwisata sebagai lokomotif baru pertumbuhan ekonomi Indonesia sudah senyatanya merupakan pilihan kebijakan strategis yang tepat, merujuk pada hasil Studi Bank Dunia, yang menegaskan peran penting sektor pariwisata bagi pembangunan berkelanjutan, mendorong pertumbuhan GDP, meningkatkan intensitas perdagangan internasional, menaikkan investasi global, disamping berperan dalam mengangkat negara-negara berpendapatan rendah (lowincome countries)'”.

Memasuki milenium baru kebutuhan pariwisata berkembang sangat pesat dan menjadi kebutuhan semua kalangan dan generasi, ini disebabkan karena pergeseran dan perubahan pandangan hidup dari prinsip ekonomi konfensional kepada ekonomi pengalaman, generasi sekarang lebih senang mengalokasikan dananya untuk menikmati sesuatu yang menciptakan pengalaman dan kenangan yang dapat dia banggakan, salah satunya berwisata ke spot-spot wisata baru hanya untuk menikmati suasana alam dan berfoto-foto.

Karena perubahan dan pergeseran pandangan tersebut maka pariwisata mesti ditangani dengan serius sesuai perkembangan zaman tanpa menghilangkan ciri khas daerah dan penanganan ini harus melibatkan semua pemangku kepentingan. Promosi wisata merupakan cara ampuh untuk memperkenalkan objek wisata bagi para wiasatawan sekaligus menimbulkan minat berkunjung ke daerah wisata yang bersangkutan. 
Objek wisata akan berkembang menjadi suatu tujuan wisata bila didukung oleh fasilitas, pelayanan, jasa, pemasaran,dan aksesibilitas fasilitas wisata yang memadai. Ketersediaan fasilitas wisata yang representatif, pelayanan, jasa, pemasaran,dan aksesibilitas yang tidak mampu memenuhi kebutuhan wisatawan menjadi persoalan di sebagian besar objek wisata.

Wisatawan akan termotivasi untuk melakukan perjalanan wisata bila dia memiliki persepsi yang baik akan objek wisata yang dituju. Lewat persepsi, wisatawan menentukan pilihan dan perilakunya, oleh karena itu persepsi wisatawan memberikan gambaran akan terpenuhinya harapan wisatwan ketika terjadi penyerahan jasa wisata di tempat wisata, dengan demikian maka persepsi wisatawan merupakan dasar pertimbangan pengembangan objek wisata sesuai dengan kebutuhan pasar.

Provinsi Papua Barat sebagaimana diketahui dikarunai sumber daya alam yang melimpah serta memiliki berbagai potensi pariwisata mulai dari pesisir pantai sampai pegunungan. Kabupaten Manokwari Selatan salah satu yang memiliki objek-objek wisata pantai yang indah, sayangnya hampir semua hanya sebatas rintisan dan belum mendapat perhatian dari pemerintah daerah. Salah satu objek wisata pantai yang paling digemari oleh masyarakat adalah objek wisata pantai Seuwmyen, pantai ini memiliki atraksi wisata yang menjanjikan, dengan pemandangan yang masih asli, pohon-pohon yang rindang, serta pasir pantai yang menghampar luas. Pemandangan yang indah kemudian di batasi dengan ketidak tersediaan produk wisata yang memadai.

Dengan tidak mengabaikan setiap upaya yang telah dialakukan oleh masyarakat Kampung Oransbari maka perlu diperhatikan apa yang menjadi kebutuhan pengunjung objek wisata Pantai Sauwmyen, bahwa berwisata merupakan kebutuhan sekunder yang harus dipenuhi oleh setiap Individu setelah kebutuhan primernya terpenuhi, semua orang mengambil keputusan berwisata karena adanya jasa kenyamanan (Emenitis) yang ditawarkan dan itulah yang menjadi harapan dan kebutuhan dari mereka.

Keinginan akan rasa nyaman akan mendorong upaya memenuhi kenyamanan tersebut lewat dibangunnya fasilitas rekreasi, tempat-tempat bersantai, sarana bermain, dan fasilitas public lainnya, kesimpulannya adalah faktor emenitis merupakan pengungkit pembangunan dan pembangunan kawasan dan perkotaan.

Dari hasil wawancara, rata-rata wistawan pantai Sauwmyen mengatakan bahwa objek wisata ini memiliki pemandangan yang menarik, hutan yang masih asli, namun ada beberapa hal yang perlu menjadi perhatian karena tempat ini belum representative untuk menciptakan kenyamanan (Faktor Emenitis) yang seharusnya dijual kepada para pengunjung wisata pantai Sauwmyen.

Harapan besar akan terpenuhi kenyamanan berwisata berbading terbalik dengan kenyataan pelayanan yang dirasakan tidak maksimal oleh pengunjung, mulai dari jalan masuk untuk masuk ke kawasan wisata, tidak jelasnya petugas parkir, tidak adanya wahana permainan, tidak adanya fasilitas kebersihan, tidak adanya pos keamanan dan fasilitas kesehatan, serta masih banyak lagi faktor yang tidak berpihak pada kenyaman pengunjung wisata.

Semua permasalahan yang sudah disebutkan diatas bila kemudian disandingkan dengan tujuan pembangunan sektor pariwisata maka seharusnya pemerintah kabupaten Manokwari selatan memberikan perhatian lebih kepada sektor pariwisata yang nyatanya semenjak pemekaran wilayah hingga kini belum ada tanda-tanda campur tangan dan kebijakan pemerintah yang mengarah pada pengembangan sektor pariwisata di Manokwari Selatan terutama wisata pantai Sauwmyen penelitian ini kemudian dilakukan dengan judul "Analisis Persepsi Pengunjung terhadap ketersediaan Produk Wisata di Pantai Sauwmyen" untuk menjaring persepsi pengunjung wisata terhadap produk wisata yang selanjutnya akan menghasilkan strategi-strategi pengembangan kedepan agar emenitis yang adalah faktor utama tujuan seseorang berwisata bisa tercapai. Berdasarkan paparan latar belakang maka yang menjadi permasalahan dalam penelitian ini adalah:

1. Bagaimana Persepsi Wisatawan terhadap Ketersediaan Produk wisata di Objek Wisata Pantai Sauwmyen?

2. Bagaimana tingkat Kepuasan Wisatawan Terhadap Objek Wisata Pantai Sauwmyen?

3. Bagaimana strategi pengembangan objek wisata Pantai Sauwmyen?

Dengan demikian tujuan penelitian adalah untuk mengetahui dan menganalisis persepsi wisatawan terhadap ketersediaan produk, mengetahui tingkat kepuasan wisatawan terhadap objek dan merumuskan strategi pengembangan objek wisata 
pantai Sauwmyen.

\section{METODE PENELITIAN}

Populasi dari penelitian ini adalah setiap orang yang mengunjungi objek wisata pantai Sauwmyen dan sampel yang digunakan 68 orang. Pertimbangan jumlahnya sesuai hasil survey awal yang didapati pada hari ramai atau libur (Sabtu dan Minggu). Biasanya jumlah kunjungan wisata ke objek wisata pantai Sauwmyen berkisar antara 80 sampai dengan 100 orang. Selanjutnya diasumsikan bahwa jumlah pengunjung objek wisata bisa mencapai 180 orang dalam seminggu di hari Sabtu dan Minggu, dan jarang sekali ada pengunjung di hari-hari lain selain dua hari tersebut. Untuk menentukan besarnya jumlah sampel digunakan rumus slovin ( Prasetyo dan Jannah, 2005:137), yaitu :

$$
\begin{gathered}
\mathrm{n}=\frac{N}{1+N e^{2}} \\
n=\frac{180}{1+(180)(0,10)^{2}}=68,28 \approx 68 \text { orang }
\end{gathered}
$$

Di mana:

$\mathrm{n}=$ ukuran sampel

$\mathrm{N}=$ ukuran populasi

$\mathrm{e}=$ nilai kritis (batas ketelitian) yang diinginkan (persen kelonggaran ketidaktelitian karena kesalahan penarikan sampel).

Atas dasar rumus tersebut, jumlah sampel yang ditetapkan dengan nilai kritis sebesar $10 \%$, jumlah sampel yang dibutuhkan adalah 68 orang pengunjung wisata pantai Sauwmyen.

Teknik Pengumpulan Data yang digunakan adalah teknik survey. Oleh karena itu, untuk mendapatkan data, maka diperlukan metode pengumpulan data yang dipergunakan adalah sebagai berikut:

1. Wawancara kepada yang berhak dan berwenang memberikan data yang berhubungan dengan penelitian ini, yaitu pengunjung wisata.

2. Daftar pertanyaan (questioner), teknik pengumpulan data dengan memberikan atau menyebarkan daftar pertanyaan kepada responden pengguna jasa pengiriman yang menjadi sampel, yang memberikan respon atas daftar pertanyaan tersebut.

3. Studi dokumentasi yaitu dengan mengumpulkan dan mempelajari data-data yang relevan dan mendukung penelitian antara lain yang diperoleh dari kantor BPS, kantor desa, dan perpustakaan serta data lain yang mendukung penelitian.
Teknik Analisis yang digunakan adalah deskriptif dimana data yang telah terkumpul selanjutnya dianalisis secara kuantitatif dan kualitatif. Penelitian kuantitatif pada umumnya dilakukan pada sampel yang diambil secara random, sehingga kesimpulan hasil penelitian dapat digeneralisasikan pada populasi dimana sampel tersebut diambil. Sebelum data yang didapatkan dari hasil kuisioner ini diolah, maka terlebih dahulu dilakukan pengujian validitas dan reliabilitas kuisioner. Tujuan pengujian ini adalah untuk mengetahui apakah isi atau data dari butirbutir pertanyaan tersebut sudah sah (valid) dan handal (reliable). Apabila data dari butir-butir pertanyaan tersebut sudah valid dan reliable maka data tersebut dapat digunakan untuk mengukur kandungan instrumen yang ada.

Uji reliabilitas dilakukan dengan uji statistik Cronbach Alpha $(\alpha)$. Suatu konstruk dikatakan reliable apabila memberikan nilai Alpha Cronbach > 0,60 (Ghozali, 2001).

Dimana :

$$
\alpha=\left[\frac{k}{k-1}\right]\left[1-\frac{\sum \sigma_{b}^{2}}{\sigma_{t}^{2}}\right]
$$

$\propto=$ koefisien reliabilitas instrumen (cronbach alpha)

$\mathrm{k}$ = jumlah variabel data yang membentuk variabel laten

$\sum \sigma_{b}^{2}=$ total varians butir

$\sum \sigma_{\mathrm{t}}^{2}=$ total varians

Untuk melakukan analisis validitas data digunakan uji korelasi Product Momment. Suatu indikator dikatakan valid apabila besarnya nilai signifikansi $<0,05$.

Pengujian validitas instrumen dilakukan untuk menguji apakah instrumen yang digunakan telah valid/sesuai. Pengujian ini dilakukan dengan perhitungan nilai $\mathrm{T}$ :

$$
T_{\text {hitung }}=R_{b t} \frac{n-2}{\sqrt{1-R_{b t}^{2}}}
$$

Dimana :

$T_{\text {hitung }}=$ Nilai $\mathrm{T}$

$\mathrm{n}=$ jumlah responden

$R_{b \mathrm{t}}=$ corrected item total correlation

Nilai $\mathrm{T}$ ditentukan berdasarkan tabel total correlation. Butir pertanyaan dalam kuesioner dinyatakan valid jika nilai Corrected Item Total Correlation Rbt $>$ ttabel. 
Untuk menjawab pertanyaan penelitian yang pertama dan ke tiga maka dipakai pendekatan IPA (Importand Performance Analissys). IPA digunakan untuk melihat persepsi responden terhadap indikator-indikator Pendudkung Parawisata yang Meliputi Atraksi Wisata, Eksebilitas, dan Kondisi Fasilitas tempat wisata. Adapun rumus yang digunakan adalah :

Dimana :

$$
T k i=\frac{X i}{Y i} \times 100 \%
$$

Tki = tingkat kesesuaian responden

$\mathrm{Xi}=$ skor penilaian Jasa Yang diperoleh (atraksi wisata, eksebelitas, kondisi fasilitas tampat wisata) di Pantai Sauwmyen

$\mathrm{Yi}=$ skor penilaian konsumen akan harapannya

Selanjutnya sumbu mendatar (X) akan diisi oleh skor tingkat pelaksanaan kinerja, sedangkan sumbu tegak (Y) akan diisi oleh skor tingkat harapan. Dalam hal ini penyederhanaan rumus, maka untuk setiap faktor yang mempengaruhi kepuasan konsumen/ pelanggan dengan :

Dimana :

$$
\widetilde{\mathrm{X}}=\frac{\sum \mathrm{Xi}}{\mathrm{n}} \quad \text { dan } \quad \widetilde{Y}=\frac{\sum \mathrm{Yi}}{\mathrm{n}}
$$

$\widetilde{\mathrm{X}}=$ skor rata-rata tingkat kinerja

$\tilde{Y}=$ skor rata-rata tingkat harapan

$\mathrm{N}=$ jumlah responden
(Supranto 2011:239-243). Dalam penelitian ini terdapat dua buah variabel yang diwakilkan oleh huruf $\mathrm{X}$ dan huruf $\mathrm{Y}$, dimana $\mathrm{X}$ merupakan tingkat kinerja atau ketersediaan produk wisata, dan Y merupakan tingkat harapan konsumen, tingkat kesesuaian inilah yang akan menentukan prioritas peningkatan strategi.

Diagram Kartesius merupakan suatu bangun yang dibagi atas empat bagian yang dibatasi oleh garis berpotongan tegaklurus pada titik-titik $(\mathrm{X}, \mathrm{Y})$ dimana $\mathrm{X}$ merupakan rata-rata dari rata-rata skor tingkat kinerja seluruh faktor yang mempengaruhi kepuasan pelanggan/konsumen. Sedangkan $\mathrm{K}$ adalah banyaknya indikator atau sub indikator.

Rumus selanjutnya :

$\overline{\bar{x}}=\frac{\sum \mathrm{Xi}}{\mathrm{n}}=\begin{aligned} & \text { rata-rata dari rata-rata skor tingkat } \\ & \text { penyerahan jasa }\end{aligned}$

$\overline{\bar{Y}}=\frac{\sum \mathrm{Yi}}{\mathrm{n}}=\begin{aligned} & \text { rata-rata dari rata-rata skor tingkat } \\ & \text { harapan }\end{aligned}$

Hasil perhitungan dari rumus-rumus tersebut kemudian dimasukkan ke dalam diagram Kartesius. Dari sini, diketahui mana indikatorindikator yang merupakan prestasi dan perlu dipertahankan. Selain itu juga diketahui mana indikator-indikator yang kualitasnya tidak bagus.

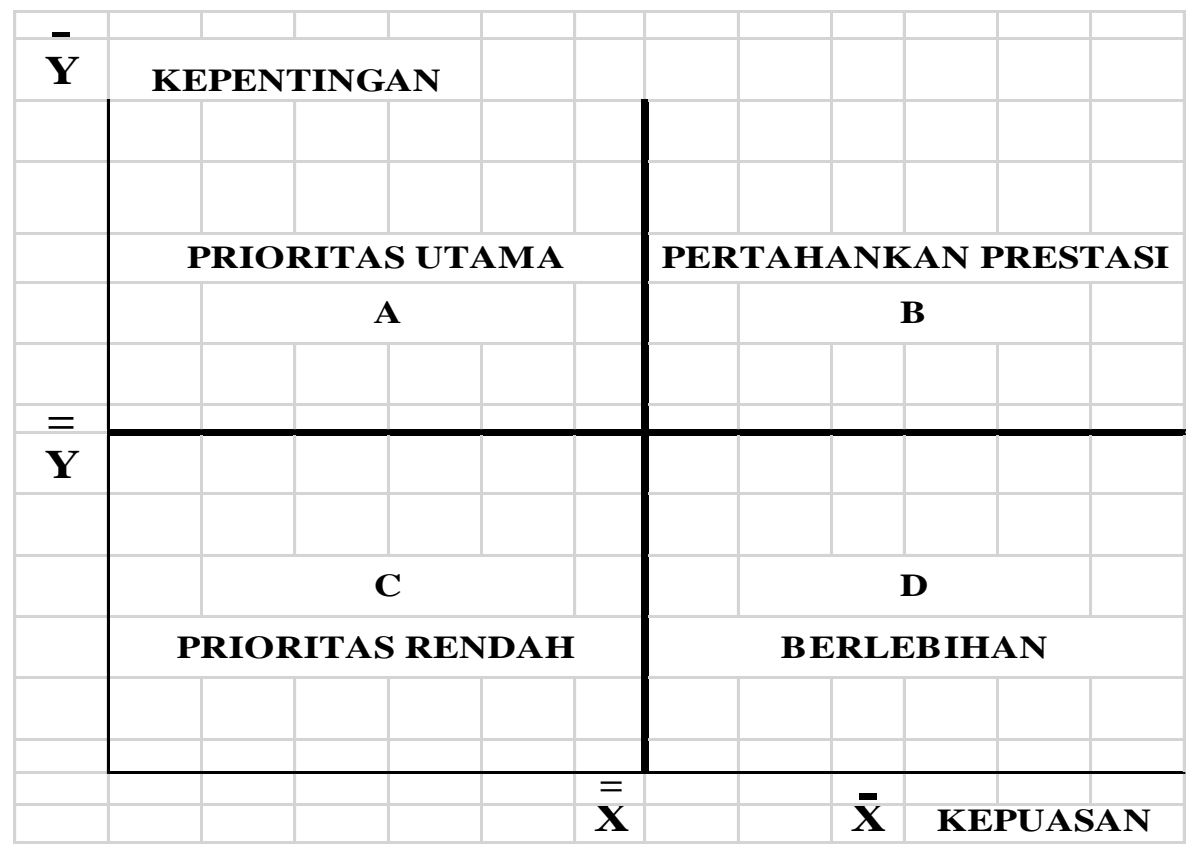

Gambar 1. Diagram Kartesius 
Untuk dapat melihat posisi penempatan data yang telah dianalisis tersebut, maka dapat dibagi empat bagian:

a. Kuadran A, "prioritas utama" berarti memiliki skor yang tinggi dari sisi tingkat harapan namun memiliki skor terendah dari sisi kinerja. Hasil ini menunjukkan letak ketidakpuasan pelanggan.

b. Kuadran B, "pertahankan prestasi" berarti memiliki skor yang tinggi baik dari sisi tingkat harapan maupun pada sisi tingkat kinerja. Aspek-aspek pada kategori ini merupakan aspek ideal, karena di sini menunjukkan bahwa organisasi memiliki keunggulan di bidang yang dianggap penting oleh pelanggan.

c. Kuadran C, "prioritas rendah" berarti baik skor tingkat harapan maupun tingkat kinerja bernilai rendah. Aspek-aspek pada kelompok ini dapat diabaikan oleh manajemen di masa yang akan datang.

d. Kuadran D, "berlebihan" berarti skor tingkat harapan rendah namun skor tingkat kinerja tinggi. Hasil ini menunjukkan bahwa organisasi terlalu fokus pada aspek yang berdampak kecil terhadap kepuasan pelanggan sehingga sumbernya dapat dialokasikan pada aspek lain yang mempunyai tingkat harapan tinggi tetapi masih rendah skornya pada tingkat kinerja.

Untuk menjawab pertanyaan penelitian yang tiga menggunakan Metode Customer Satisfaction Index (CSI). CSI merupakan indek untuk menentukan tingkat kepuasan pelanggan secara menyeluruh dengan pendekatan yang mempertimbangkan tingkat kepentingan dari atribuut-atribut produk atau jasa yang diukur. CSI memberikan data yang jelas mengenai tingkat kepuasan pelanggan sehingga pada satuan waktu tertentu dapat melakukan evaluasi secara berkala untuk memperbaiki apa yang kurang dan meningkatkan pelayanan yang dinilai customer adalah sebuah nilai lebih.

Untuk mengetahui besarnya CSI, maka dapat dilakukan langkah-langkah sebagai berikut (Aritonang, dalam Syukri 2014:108):

1. Menentukan Mean Importance Score (MIS) tiap-tiap variabel,

2. Membuat Weight Factors (WF) per variabel. Bobot ini merupakan persentasenilai $M I S$ per variabel terhadap total $M I S$ seluruh variable,

3. Menentukan Mean Satisfaction Score (MSS) tiap atribut,
4. Membuat Weight Score (WSk) tiap variabel. Bobot ini merupakan perkalian antaraWFk dengan MSSk, dan

5. Menentukan Customer Satisfaction Index (CSI).

Atau :

$$
\mathrm{CSI}=\frac{\mathrm{WT}}{5}
$$

Dimana:

$$
\begin{aligned}
\mathrm{WT} & =\sum \mathrm{WS} \\
\mathrm{WS} & =\mathrm{WF} \times \mathrm{MSS} \\
\mathrm{WF} & =\mathrm{MIS} / \sum \mathrm{MIS} \\
\mathrm{MSS} & =\text { Mean Satifaction Score } \\
\mathrm{MIS} & =\text { Mean Importance Score } \\
\mathrm{WF} & =\text { Weight Factors } \\
\mathrm{WS} & =\text { Weight Score } \\
\mathrm{WT} & =\text { Weight Total }
\end{aligned}
$$

Hasil perhitungan kemudian diuji dengan menggunakan kriteria tingkat kepuasan dengan kriteria sebagai berikut:

Tabel 1. Kriteria Pengujian Tingkat Kepuasan Pengunjung Wisata

\begin{tabular}{ccc}
\hline No & Nilai CSI $(\%)$ & Keterangan (CSI) \\
\hline 1 & $81 \%-100 \%$ & Sangat Puas \\
\hline 2 & $66 \%-80.99 \%$ & Puas \\
\hline 3 & $51 \%-65.99 \%$ & Cukup Puas \\
\hline 4 & $35 \%-50.99 \%$ & Kurang Puas \\
\hline 5 & $0 \%-34.99 \%$ & Tidak Puas \\
\hline
\end{tabular}

Nilai maksimum CSI adalah $100 \%$. Nilai CSI 50\% atau lebih rendah menandakan kinerja pelayanan yang kurang baik. Nilai CSI $80 \%$ atau lebih tinggi mengindikasikan pengguna merasa puas terhadap kinerja pelayanan.

Atraksi wisata adalah objek wisata yang sudah dipilih atau ditentukan oleh wisatawan dan akan mempengaruhi calon-calon wisatawan lainnya. salah satu elemen dalam atraksi wisata yaitu atraksi wisata alam pantai Sumyen Distrik Oransbari Kabupaten Manokwari Selatan.

Kondisi atraksi wisata Pantai Sauwmyen yang dapat diukur antara lain:

a. Keunikan dari Pantai Sauwmyen

b. Keindahan pemandangan Pantai Suwmiyen

c. Kenyamanan Objek wisata Pantai Suwmiyen

d. Kesejukan Pantai Sauwmiyen

e. Kebersihan Pantai Sauwmyen.

Elemen-elemen yang termasuk dalam aksebilitas adalah yang mempengaruhi biaya, kelancaran, dan 
kenyamanan terhadap seorang wisatawan yang akan menempuh suatu atraksi.

Aksebilitas Pantai Sauwmyen yang dapat diukur antara lain:

a. Bagaimana kualitas jalan menuju pantai Sauwmyen

b. Bagaimana keterjangkauan angkutan umum

c. Kualitas jalan utama yang terdekat

d. Bagaimana kondisi rambu lalu lintas

e. Bagaimana penunjuk arah menuju pantai Sauwmyen

Fasilitas yang terdapat didalam suatu atraksi atau berkenan dengan suatu atraksi yang memungkinkan pengunjung untuk menginap dan dengan kata lain untuk menikmati dan berpartisipasi didalam suatu atraksi wisata. Kondisi Fasilitas Tempat Wisata Pantai Suwmyen yang dapat diukur antara lain:

a. Luas tempat parkir

b. Keamanan tempat parkir

c. Keterampilan juru parkir

d. Kebersihan Toilet

e. Jumlah toilet

f. Akses pusat informasi

g. Tempat istirahat

h. Rumah makan

i. Sarana kesehatan

j. Ketersediaan tempat sampah

k. Toko cinderamata

1. Fasilitas penginapan

\section{HASIL DAN PEMBAHASAN}

\section{Uji Validitas dan Reabilitas Kuisioner}

Uji validitas adalah uji yang digunakan untuk menunjukkan sejauh mana alat ukur yang digunakan dalam suatu mengukur apa yang diukur. Ghozali (2009) menyatakan bahwa uji validitas digunakan untuk mengukur sah, atau valid tidaknya suatu kuesioner. Suatu kuesioner dikatakan valid jika pertanyaan pada kuesioner mampu untuk mengungkapkan sesuatu yang akan diukur oleh kuesioner tersebut.

Untuk melakukan uji validitas ini menggunakan program SPSS. Teknik pengujian yang sering digunakan para peneliti untuk uji validitas adalah menggunakan korelasi Bivariate Pearson (Produk Momen Pearson). Analisis ini dengan cara mengkorelasikan masing-masing skor item dengan skor total. Skor total adalah penjumlahan dari keseluruhan item. Item-item pertanyaan yang berkorelasi signifikan dengan skor total menunjukkan item-item tersebut mampu memberikan dukungan dalam mengungkap apa yang ingin diungkap valid. Jika $r$ hitung $\geq r$ tabel (uji 2 sisi dengan sig. 0,05) maka instrumen atau itemitem pertanyaan berkorelasi signifikan terhadap skor total (dinyatakan valid). Untuk melihat nilai r-tabel dipakailah rumus $\mathrm{df}=\mathrm{N}-2$ pada tingkat signifikan $5 \%$, dengan $\mathrm{N}$ sebesar 68 maka didapati nilai r-tabel adalah sebesar 0,2387. Berikut hasil pengujian validitas dengan SPSS 20.

Berdasarkan hasil perhitungan dan pengujian ditemukan semua nilai r-hitung lebih besar dari nilai r-tabel yang berarti instrumen atau item-item pertanyaan tentang kondisi produk wisata Pantai Sauwmyen menurut persepsi pengunjung berkorelasi signifikan terhadap skor total (dinyatakan valid).

Setelah melakukan uji validitas selanjutnya adalah uji reliabilitas, Ghozali (2009) menyatakan bahwa reliabilitas adalah alat untuk mengukur suatu kuesioner yang merupakan indikator dari peubah atau konstruk. Suatu kuesioner dikatakan reliabel atau handal jika jawaban seseorang terhadap pernyataan adalah konsisten atau stabil dari waktu ke waktu. Reliabilitas suatu test merujuk pada derajat stabilitas, konsistensi, daya prediksi, dan akurasi. Pengukuran yang memiliki reliabilitas yang tinggi adalah pengukuran yang dapat menghasilkan data yang reliabel. Jadi sebenarnya uji reabilitas bertujuan untuk mengukur tingkat konsistensi responden dalam menjawab setiap pertanyaan dalam kuisioner penelitian. Penelitian dianggap dapat diandalkan bila memberikan hasil yang konsisten untuk pengukuran yang sama. Tidak bisa diandalkan bila pengukuran yang berulang itu memberikan hasil yang berbedabeda.

Pengujian reabilitas kuisioner dilakukan dengan membandingkan nilai Cronbach's Alpha berdasarkan hasil perhitungan SPSS yang harus lebih besar dari 0,60 yang berarti jawaban responden adalah reliable atau konsisiten dan dapat diandalkan, dan sebaliknya jika nilai Cronbach's Alpha berdasarkan hasil perhitungan SPSS adalah lebih kecil dari 0,60 maka jawaban responden adalah tidak reliable atau tidak konsisiten dan tidak dapat diandalkan.

Berdasarkan hasil uji validitas didapati nilai Cronbach-Alpha dari Kepentingan adalah 0,926 dan Kinerja sebesar 0,860 yang berarti kedua nilai kepentingan dan kinerja lebih besar dari 0,60, dengan demikian reponden konsiten dalam menjawab semua pertanyaan.

\section{Persepsi Pengunjung Wisata Terhadap Ketersediaan Produk Wisata Pantai Sauwmyen}

Dari tabel 2 terlihat bahwa persepsi wisatawan terhadap performance (kenyataan yang didapati) 
adalah sebesar 3,67 serta importance (harapan/kepentingan) mendapat persepsi sebesar 4,83 dengan tingkat kesesuaiannya mencapai 0,76 atau $76 \%$ berada pada Tingkat kesesuaian <
$100 \%$ berarti tingkat kinerja atribut atraksi wisata belum sesuai dengan kepentingan pengunjung wisata Pantai Sauwmyen.

Tabel 2. Persepsi Tentang Kondisi Atraksi Wisata Pantai Sauwmyen

\begin{tabular}{clrrrc}
\hline No & \multicolumn{1}{c}{ Kondisi Atraksi Wisata } & Kepentingan & Kinerja & Kesesuaian & Kategori \\
\hline A & Keunikan Pantai Sauwmyen & 4,81 & 4,15 & 0,862 & M \\
\hline B & $\begin{array}{l}\text { Keindahan Pemandangan di Pantai } \\
\text { Sauwmyen }\end{array}$ & 4,84 & 4,47 & 0,924 & SM \\
\hline C & $\begin{array}{l}\text { Kenyamanan Objek Wisata Pantai } \\
\text { Sauwmyen }\end{array}$ & 4,84 & 3,32 & 0,687 & CM \\
\hline D & Kesejukan Pantai Sauwmyen & 4,81 & 4,40 & 0,914 & SM \\
\hline E & Kebersihan Pantai Sauwmyen & 4,84 & 2,03 & 0,419 & KM \\
\hline & Rerata & 4,83 & 3,67 & 0,76 & M \\
\hline
\end{tabular}

\section{Sumber: Data primer diolah, 2020}

Selanjutnya bila ditinjau perbutir indikator untuk point A rata-rata persepsi responden akan tingkat kinerja adalah sebesar 4,15 berada pada rentang $3,401-4,200$ artinya kinerja produk wisata Memuaskan (M), indikator B dipersepsikan pada angka 4,47 berada pada rentang 4,201 - 5,000 kategori Sangat memuaskan, indikator C 3,32 berada pada rentang 2,601-3,400 artinya kinerja produk wisata Cukup memuaskan (CM), indikator D 4,40 berada pada rentang 4,201 - 5,000. Artinya kinerja produk wisata Sangat memuaskan (SM), dan terakhir indikator E 2,03 berada pada rentang 1,801 - 2,600 artinya kinerja produk wisata Kurang memuaskan (KM).

Tabel 3. Persepsi Pengunjung Wisata Terhadap Aksebilitas

\begin{tabular}{|c|c|c|c|c|c|}
\hline No & Aksebilitas & Kepentingan & Kinerja & Kesesuaian & Kategori \\
\hline $\mathrm{F}$ & $\begin{array}{l}\text { Bagaimana Kualitas Jalan Menuju } \\
\text { Pantai Sauwmyen }\end{array}$ & 4,74 & 3,35 & 0,708 & $\mathrm{CM}$ \\
\hline $\mathrm{G}$ & $\begin{array}{l}\text { Bagaimana Keterjangkauan Angkutan } \\
\text { Umum Ke Pantai Sauwmyen }\end{array}$ & 4,81 & 2,90 & 0,602 & $\mathrm{CM}$ \\
\hline $\mathrm{H}$ & $\begin{array}{l}\text { Kulitas jalan utama yang terdekat } \\
\text { dengan Pantai Sauwmyen }\end{array}$ & 4,87 & 2,96 & 0,607 & $\mathrm{CM}$ \\
\hline I & $\begin{array}{l}\text { Bagaimana Kondisi Rambu Lalulitas } \\
\text { Menuju Pantai Sauwmyen }\end{array}$ & 4,65 & 1,91 & 0,411 & KM \\
\hline $\mathrm{J}$ & $\begin{array}{l}\text { Bagaimana Kondisi Penunjuk Arah } \\
\text { Menuju Pantai Sauwmyen }\end{array}$ & $\frac{4,91}{4,79}$ & $\frac{1,91}{2,61}$ & $\begin{array}{r}0,389 \\
0,54\end{array}$ & KM \\
\hline
\end{tabular}

\section{Sumber: Data primer diolah, 2020}

Dari tabel 3 didapati persepsi wisatawan terhadap aksebilitas menuju Pantai Sauwmyen angka kinerja bernilai 2,61 yang kalau dibulatkan nilainya 3 artinya Baik, aspek harapan/kepentingan diperoleh skor 4,79 dibulatkan menjadi 5 artinya sangat penting sekali, dengan tingkat kesesuaian sebesar 0,54 atau $54 \%$ berada pada Tingkat kesesuaian $<100 \%$ berarti tingkat kinerja atribut kondisi eksebilitas menuju objek wisata Pantai Sauwmyen belum sesuai dengan kepentingan pengujung wisata.

Selanjutnya bila ditinjau perbutir indikator untuk point F (Kualitas Jalan Menuju Pantai Sauwmyen) rata-rata persepsi responden akan tingkat kinerja adalah sebesar 3,35 berada pada rentang 2,601-3,400 artinya kinerja produk wisata Cukup memuaskan (CM), indikator G (Keterjangkauan Angkutan Umum Ke Pantai Sauwmyen) dipersepsikan pada angka 2,90 berada pada rentang 2,601 - 3,400 artinya kinerja produk wisata Cukup memuaskan (CM), indikator $\mathrm{H}$ (Kualitas jalan utama yang terdekat dengan Pantai Sauwmyen) 2,96 berada pada rentang 2,601 - 3,400 artinya kinerja produk wisata Cukup memuaskan (CM), indikator I (Kondisi Rambu Lalulitas Menuju Pantai Sauwmyen) 1,91 berada pada rentang 1,801 2,600 artinya kinerja produk wisata Kurang memuaskan (KM), Indikator J (Kondisi Penunjuk Arah Menuju Pantai Sauwmyen) 1,91 berada pada rentang 1,801 -2,600 artinya kinerja produk wisata Kurang memuaskan (KM).

Tabel 4 berikut menunjukkan kinerja dan harapan 
pengunjung wisata terhadap kondisi fasilitas tempat wisata Pantai Sauwmyen.

Tabel 4. Persepsi Wisatawan Tentang Kondisi Fasilitas Tempat Wisata

\begin{tabular}{clrrrl}
\hline No & Kondisi Fasilitas Tempat Wisata & Kepentingan & \multicolumn{1}{c}{ Kinerja } & \multicolumn{1}{c}{ Kesesuaian } & Kategori \\
\hline L & Luas Tempat Parkir & 4,84 & 2,69 & 0,556 & CM \\
\hline M & Keamanan Tempat Parkir & 4,75 & 2,26 & 0,477 & KM \\
\hline N & Ketrampilan Juru Parkir & 4,50 & 1,62 & 0,359 & TM \\
\hline O & Keberhasilan Toilet & 4,91 & 1,79 & 0,365 & TM \\
\hline P & Jumlah Toilet & 4,75 & 2,18 & 0,458 & KM \\
\hline Q & Akses Pusat Informasi & 4,84 & 2,37 & 0,489 & KM \\
\hline R & Tempat Istirahat & 4,88 & 2,97 & 0,608 & CM \\
\hline S & Rumah Makan & 4,76 & 1,44 & 0,302 & TM \\
\hline T & Sarana Kesehatan & 4,76 & 2,40 & 0,503 & KM \\
\hline U & Ketersediaan Tempat Sampah & 4,96 & 1,60 & 0,323 & TM \\
\hline V & Toko Cindra Mata & 4,62 & 1,34 & 0,290 & TM \\
\hline V & Fasilitas Penginapan & 4,62 & 1,59 & 0,344 & TM \\
\hline & & 4,77 & 2,02 & 0,42 & KM \\
\hline
\end{tabular}

\section{Sumber: Data primer diolah, 2020}

Dari tabel 4 terlihat bahwa persepsi wisatawan terhadap kondisi fasilitas wisata di Pantai Sauwmyen dari aspek performance (Kenyataan yang didapat) hanya bernilai 2,02 yang kalau dibulatkan nilainya 2 artinya Tidak Baik, sementara dari aspek importance (Harapan/ kepentingan) diperoleh skor 4,77 dibulatkan menjadi 5 bernilai Sangat Penting Sekali, dengan tingkat kesesuaian antara kinerja terhadap harapan adalah sebesar 0,42 atau $42 \%$ berada pada Tingkat kesesuaian $<100 \%$ berarti tingkat kinerja atribut yang berarti kinerja kondisi fasilitas di tempat wisata belum sesuai dengan keinginan pengunjung wisata Pantai Sauwmyen.

Selanjutnya bila ditinjau dari indikator maka persepsi reponden adalah sebagai berikut, indikator L (Luas Tempat Parkir) adalah sebesar 2,69 berada pada interval Nilai 2,601 - 3,400 Cukup memuaskan (CM), nilai persepsi terhadap indikator $\mathrm{M}$ (Keamanan Tempat Parkir) adalah sebesar 2,26 berada pada interval Nilai 1,801 2,600 kategori Kurang memuaskan (KM), nilai persepsi terhadap indikator N (Ketrampilan Juru Parkir) adalah sebesar 1,62 berada pada interval Nilai Nilai 1,000 - 1,800 kategori Tidak memuaskan (TM). Selanjutnya nilai persepsi terhadap indikator $\mathrm{O}$ (Kebersihan Toilet) adalah sebesar 1,79 berada pada interval Nilai Nilai 1,000-1,800 kategori Tidak memuaskan (TM), indikator P (Jumlah Toilet) mendapat penilaian sebesar 2,18 berada pada interval Nilai 1,801 - 2,600 kategori Kurang memuaskan $(\mathrm{KM})$, untuk indikator Q (Akses ke pusat Informasi) mendapatkan nilai perspsi sebesar 2,37 berada pada interval $\mathrm{N}$ ilai 1,801 - 2,600 kategori Kurang memuaskan (KM).

Indikator selanjutnya adalah indikator $\mathrm{R}$ (Tempat Istirahat) dimana responden memberikan persepsi sebesar 2,97 bedara pada interval nilai 2,601 - 3,400 kategori Cukup memuaskan (CM), selanjutnya indikator S (Rumah Makan) dipersipsikan oleh responden sebesar 1,44 ada pada interval nilai 1,000 - 1,800 berada pada kategori Tidak memuaskan (TM), indikator selanjunya adalah indikator $\mathrm{T}$ (Sarana Kesehatan) yang oleh responden dipersepsikan pada nilai 2,40 berada pada interval nilai 1,801 - 2,600 kategori Kurang memuaskan $(\mathrm{KM})$, selanjutnya adalah indikator $\mathrm{U}$ (Ketersediaan Tempat Sampah) dengan nilai persepsi sebesar 1,60 berada pada inetrval nilai $1,000-1,800$ kategori Tidak memuaskan (TM), selanjunya adalah indikator V (Toko Cindera Mata) indikator ini menurut persepsi responden diberi nilai 1,34 dan berada pada interval nilai $1,000-1,800$ kategori Tidak memuaskan (TM), dan yang terakhir adalah indikator W (Fasilitas Penginapan) yang oleh responden dipersepsikan pada nilai 1,59 berada pada interval nilai $1,000-1,800 \quad$ kategori Tidak memuaskan (TM).

\section{Analisis Kepuasan Pengunjung Wisata Pantai Sauwmyen}

Persepsi wisatawan menentukan preferensi dan perilakunya, oleh karena itu persepsi wisatawan memberikan gambaran akan terpenuhinya harapan wisatwan ketika terjadi penyerahan jasa wisata di tempat wisata, dengan demikian maka persepsi wisatawan merupakan dasar pertimbangan pengembangan objek wisata sesuai dengan kebutuhan pasar. 
Tabel 5. Perhitungan CSI Pengunjung Wisata Pantai Sauwmyen

\begin{tabular}{|c|c|c|c|c|c|c|c|}
\hline No & Indikator & \multicolumn{3}{|c|}{ MIS } & MSS & WF & WS \\
\hline 1 & Keunikan Pantai Sauwmyen & I1 & 4.81 & K1 & 4.15 & 4.57 & 18.94 \\
\hline 2 & Keindahan Pemandangan di Pantai Sauwmyen & $\mathbf{I} 2$ & 4.84 & $\mathbf{K 2}$ & 4.47 & 4.59 & 20.54 \\
\hline 3 & Kenyamanan Objek Wisata Pantai Sauwmyen & I3 & 4.84 & $\mathbf{K 3}$ & 3.32 & 4.59 & 15.27 \\
\hline 4 & Kesejukan Pantai Sauwmyen & I4 & 4.81 & K4 & 4.40 & 4.57 & 20.08 \\
\hline 5 & Kebersihan Pantai Sauwmyen & I5 & 4.84 & K5 & 2.03 & 4.59 & 9.33 \\
\hline 6 & Bagaimana Kualitas Jalan Menuju Pantai Sauwmyen & I6 & 4.74 & K6 & 3.35 & 4.50 & 15.08 \\
\hline 7 & $\begin{array}{l}\text { Bagaimana Keterjangkauan Angkutan Umum Ke Pantai } \\
\text { Sauwmyen }\end{array}$ & I7 & 4.81 & K7 & 2.90 & 4.57 & 13.23 \\
\hline 8 & $\begin{array}{l}\text { Kulitas jalan utama yang terdekat dengan Pantai } \\
\text { Sauwmyen }\end{array}$ & I8 & 4.87 & K8 & 2.96 & 4.62 & 13.66 \\
\hline 9 & $\begin{array}{l}\text { Bagaimana Kondisi Rambu Lalulitas Menuju Pantai } \\
\text { Sauwmyen }\end{array}$ & I9 & 4.65 & K9 & 1.91 & 4.41 & 8.44 \\
\hline 10 & $\begin{array}{l}\text { Bagaimana Kondisi Penunjuk Arah Menuju Pantai } \\
\text { Sauwmyen }\end{array}$ & I10 & 4.91 & K10 & 1.91 & 4.66 & 8.92 \\
\hline 11 & Luas Tempat Parkir & I11 & 4.84 & K11 & 2.69 & 4.59 & 12.37 \\
\hline 12 & Kemanan Tempat Parkir & I12 & 4.75 & K12 & 2.26 & 4.51 & 10.22 \\
\hline 13 & Ketrampilan Juru Parkir & I13 & 4.50 & K13 & 1.62 & 4.27 & 6.91 \\
\hline 14 & Keberhasilan Toilet & I14 & 4.91 & K14 & 1.79 & 4.66 & 8.37 \\
\hline 15 & Jumlah Toilet & I15 & 4.75 & K15 & 2.18 & 4.51 & 9.82 \\
\hline 16 & Akses Pusat Informasi & I16 & 4.84 & K16 & 2.37 & 4.59 & 10.88 \\
\hline 17 & Tempat Istirahat & I17 & 4.88 & K17 & 2.97 & 4.64 & 13.77 \\
\hline 18 & Rumah Makan & I18 & 4.76 & K18 & 1.44 & 4.53 & 6.52 \\
\hline 19 & Sarana Kesehatan & I19 & 4.76 & K19 & 2.40 & 4.53 & 10.85 \\
\hline 20 & Ketersediaan Tempat Sampah & $\mathbf{I 2 0}$ & 4.96 & K20 & 1.60 & 4.71 & 7.54 \\
\hline 21 & Toko Cindra Mata & I21 & 4.62 & K21 & 1.34 & 4.39 & 5.87 \\
\hline \multirow[t]{2}{*}{22} & Fasilitas Penginapan & I22 & 4.62 & K22 & 1.59 & 4.39 & 6.97 \\
\hline & Jumlah & & 105.29 & & 55.65 & & 253.57 \\
\hline
\end{tabular}

\section{Sumber: Data primer diolah, 2020}

Berdasarkan hasil perhitungan seperti pada tabel 5.13 di dapati nilai Weight Total (WT) atau Weight Score (WS) total adalah sebesar 253,57, High Score (HS) pada skala likert yang dibuat adalah 5, maka dapat ditentukan nilai CSI sebagai berikut:

$C S I=\frac{\left(\sum_{i=1}^{p} W S i\right)}{H S} \times 100 \%$

$\rightarrow C S I=\frac{(253,57)}{5} \times 100 \%=50,71 \%$

Angka 50,71\% berada pada rentan 35\%-50,9\% kriteria "kurang puas". Penyebab kurang puasnya pelanggan adalah karena hampir sebagian besar ketersediaan produk wisata belum mampu menciptakan kepuasan bagi wisatawan, hal ini sejalan dengan pendapat Sumarwan (Guspul \&
Ahmadwaludin, 2014) yang mengatakan, bila hasil dibawah harapan maka pelanggan atau konsumen akan kecewa, dan sebaliknya bila hasil sesuai dengan harapan maka konsumen akan puas. Konsumen atau pelanggan yang puas akan setia, kurang sensitif terhadap harga, memberikan komentar dan persepsi yang baik terhadap produk yang dia rasakan (Maulana, 2016).

\section{Penentuan Strategi Pengembangan}

Penentuan strategi pengembangan objek wisata Pantai Sauwmyen maka analisis performance dan importance dan GAP yang telah dilakukan sebelumnya dilanjutkan dengan analisis diagram Kartesius untuk kemudian dari hasil analisis melahirkan strategi pengembangan yang paling tidak bisa memenuhi harapan wisatawan. 


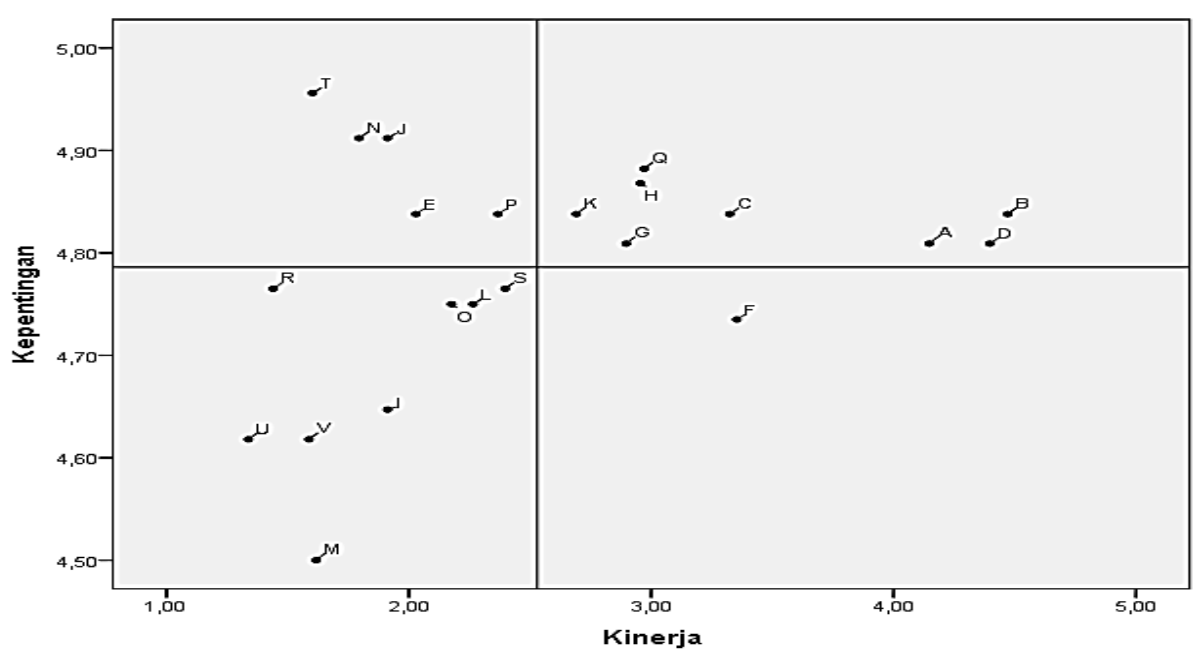

\section{Gambar 5.4 Diagram Kartesius Persepsi Pengunjung Wisata Akan Harapan Dan Kinerja}

Berdasarkan persebaran indikator atau titik GAP antara kinerja dan harapan konsumen pada empat kuadran seperti yang terlihat pada gambar 3 diatas melahirkan 4 strategi sebagai berikut:

1. Kuadran A, "prioritas utama" karena memiliki skor yang tinggi dari harapan responden, tapi dari sisi realita kinerja (penyerahan jasa) sangat rendah menurut persepsi wisatawan. Kuadran ini menunjukan tingkat ketidakpuasan wisatawan karena harapannya tidak terpenuhi, dan indikator yang termasuk dalam kuadran ini adalah E (Kebersihan Pantai Sauwmyen), J (Kondisi Penunjuk Arah Menuju Pantai), N (Kebersihan Toilet), P (Akses Pusat Informasi), $\mathrm{T}$ (Ketersediaan Tempat Sampah).

Kebijakan yang perlu dilakukan adalah pemeliharaan kebersihan pantai oleh pengelola dan pemerintah daerah, perlu adanya soasialisasi dan tindakan yang konferhensif untuk membangkitkan kesadaran pengunjung dan pengelola akan pentingnya lingkungan indikator penting dan yang bersih terutama kebersihan pantai wisata Sauwmyen. Kondisi penunjuk arah adalah merupakan salah satu indikator penting dalam pengembangan wisata, dengan penunjuk arah menuju lokasi wisata akan mempermudah pengunjung untuk menenmukan tempat dan lokasi objek wisata, oleh karena itu maka pengadaan penunjuk arah menunju objek wisata pantai Sauwyen adalah kebutuhan penting. Selanjutnya kondisi kobersihan toilet adalah masalah selanjutnya yang timbul, terdapat 4 buah toilet umum yang semuanya tidak terurus, ini harus segera diperbaiki dan dipelihara dengan baik oleh pengelola untuk memberikan dampak kenyamanan bagi pengunjung wisata, kondisi yang sama juga untuk keberadaan tempat sampah, jumlah tempat sampah yang hanya 1 buah membuat pengunjung wisata membuang sampah sembarangan oleh karena itu perlu bagi pengelola untuk menambah jumlah tempat sampah dan itu harus diatur kedudukannya agar mudah terjangkau oleh semua pengnjung. Indikator berikut adalah indikator akses informasi, hal ini menjadi persoalan karena keterjangkuan telkomsel khususnya 4G tidak sampai ke pantai Saumyen dan ini membatasi pengunjung mengakses internet untuk berbagi informasi baik secara pribadi maupun kondisi pantai Sauwmyen secepatnya, oleh karena itu maka keterjangkauan signal $4 \mathrm{G}$ sampai ke pantai Sauwmyen harus menjadi perhatian pengelola pemerintah daerah dan provider.

2. Kuadran B, "pertahankan prestasi" karena pada kuadran ini persepsi wisatawan memiliki skor yang tinggi baik dari sisi tingkat harapan maupun pada sisi tingkat kepuasan. Aspek-aspek pada kategori ini merupakan aspek ideal, karena di sini menunjukkan bahwa komponen produk wisata memiliki keunggulan yang dianggap penting oleh pelanggan. Indikator komponen produk wisata yang berada pada diagram ini meliputi A (Keunikan Pantai Sauwmyen), B (Keindahan Pemandangan Pantai Sauwmyen), C (Kenyamanan Objek Wisata Pantai Sauwmyen), D (Kesejukan Pantai Sauwmyen), G (Keterjangkauan Angkutan Umum ke Pantai Sauwmyen), H (Kualitas 
Jalan Utama yang Terdekat dengan Pantai Sauwmyen), K (Luas Tempat Parkir), Q (Tempat Istirahat).

Berdasarkan posisi indikator pada diagram ini maka merupakan keharusan bagi pengelolaan dan campur tangan pemerintah untuk menjaga dan mempertahankan kondisi produk wisata yang ada, keunikan pantai sauwmyen, keindahan pemandangan, keyamanan pantai dan kesejukan pantai yang ditandai dengan pasir yang halus, pepohonan yang rindang, terhampar di depan mata rimbun dan hijaunya hutan bakau merupakan keunikan yang dicari oleh pengunjung wisata. Selanjutnya keterjangkauan angkutan umum, kualitas jalan utama harus terus dipertahankan dan terus dipelihara agar perjalanan pengunjung wisata tetap nyaman menuju tempat wisata, selain itu tempat istirahat dan lahan parkir harus tepat dijaga kondisinya karena mampu memenuhi ekspetasi pengunjung.

3. Kuadran C, "prioritas rendah" berarti baik skor tingkat harapan maupun tingkat kinerja bernilai rendah. Aspek-aspek pada kelompok ini dapat diabaikan oleh manajemen di masa yang akan datang. I (Kondisi Rambu Lalulintas), L (Keamanan Tempat Parkir), O (Jumlah Toilet), R (Tempat Istirahat), S (Sarana Kesehatan), U (Toko Cindera Mata), V (Fasilitas Penginapan), M (Ketrampilan Juru Parkir). Walaupun indikator produk wisata pada diagram ini dianggap prioritas redah karena kinerja dan ekpekspektasi pengunujung wisata adalah rendah tetapi keberadaannya tidak bisa diabaikan karena merupakan suport sistem bagi pengembangan industri pariwisata terutama pantai Sauwmyen. Dalam jangka panjang indikatorindikator tersebut tidak bisa diabaikan bahkan dalam tahun-tahun kedepan produk wisata seperti Rambu Lalu lintas, keamanan tempat parkir, toko cendera mata, fasilitas penginapan, dan ketrampilan juru parkir akan sangat dibutuhkan bila objek wisata sudah semnakin dikenal masyarakat banyak.

4. Kuadran D, "berlebihan" berarti skor tingkat harapan rendah namun skor tingkat kinerja tinggi. Hasil ini menunjukkan bahwa organisasi terlalu fokus pada aspek yang berdampak kecil terhadap kepuasan pelanggan sehingga sumbernya dapat dialokasikan pada aspek lain yang mempunyai tingkat harapan tinggi tetapi masih rendah skornya pada tingkat kinerja.F (Kualitas jalan menuju pantai Sauwmyen).

\section{KESIMPULAN}

Berdasarkan penelitian dan pembahasan maka dapat ditarik simpulan dari penelitian ini adalah:

1. Setiap persepsi pengunjung wisata terhadap ketersediaan produk wisata sangat beragam sesuai kondisi sebenarnya di objek wisata pantai Sauwmyen. sesuai dengan atrakasi wisata secara umum memenuhi $75 \%$ tingkat keinginan pengunjung nilai kinerja 3, 67 memuaskan. Untuk indikator Aksebilitas 54\% dengan kinerja 2,62. Fasilitas tempat wisata sebesar 50,3\% dengan kinerja 2,40 kurang memuaskan.

2. CSI dengan kepuasan sebesar $50,71 \%$ secara keseluruan pengujung kurang puas dengan produk wisata.

3. Perlu adanya pengembangan oleh warga setempat dan pemerintah untuk meningkatkan kinerja, indikator produk wisata yang mempunyai kebutuhan utama bagi para pengunjung dan dapat dilihat pada responden dari setiap individu secara kepentingan maupun kinerja untuk pengembangan objek wisata pantai Sauwmyen yang lebih baik kedepan untuk digunakan oleh seluruh wisatawan yang berkujung.

\section{DAFTAR PUSTAKA}

Guspul, A., \& Ahmadwaludin. (2014). Kualitas Pelayanan, Kepuasan Dan Kepercayaan Nasabah Pada Koperasi Jasa Keuangan Syariah Di Wonosobo. Penelitian Dan Pengabdian Kepada Masyarakat Unsiq (PPKM),1(3),156-170. Https://Doi.Org/Https://Doi.Org/10.32 699/Ppkm.V1i3.253

Hugo Itamar, A.Samsu Alam, Rahmatullah, 2014, Strategi Pengembangan Pariwisata Di Kabupaten Tana Toraja, Government: Jurnal Ilmu Pemerintahan, Volume 7, Nomor 2, Juli 2014, (91-108) ISSN 1979-5645

Hertanto Eko,2017, Customer Satisfaction Index (CSI) Model 1 Manajemen Pemasaran) Satisfaction__Index_ CSI_Model 1 Manajemen Pemasaran_ 
Maulana, S. A. (2016). Pengaruh Kualitas Pelayanan Dan Harga Terhadap Kepuasan Pelanggan PT.TOI. Jurnal Ekonomi Universitas Esa Unggul, 7(2), 113-125.

Https://Www.Neliti.Com/Publications/ 78663/ Pengaruh-Kualitas-PelayananDan-Harga-Terhadap-Kepuasan-

Pelanggan-Pt-Toi

Mildeton, J.N. (2001), Merketing In Travel And Teorism; A Divison Af Reededucational And Profesional Publishing. Ltd: Oxford UK.

Nainggolan Deby Marlina, Kampana Adi I Made,2015, Stretegi Pengembangan Pantai Sawangan Sebagai Daya Tarik Wisata Nusa Dua, Jurnal Destinasi
Pariwisata ISSN: 2338-8811 Vol.3 No 2, 2015.

Pendit,S. N. (2003), Seni Budaya Falsafa, Agama Hindu, Dan Pariwisatagramedia; Jakarta.

Prasetyo, Bambang, Dan Lina Miftahul Jannah. 2011. Metode Penelitian Kuantitatif : Teori Dan Aplikasi. Rajawali Pers.

Supranto J, 2011, Pengukuran Tingkat Kepuasan Pelanggan, Untuk Menaikan Pangsa Pasar, Jakarta, Penerbt Rineka Cipta.

Syukri Siti Husna Ainu, 2014, Penerapan Customer Satisfaction Index( (CSI) Dan Analisis GAP Pada Kwalitas Pelayanan Trans Jogja Jurnal Ilmia Teknik Industry, Vol. 13, No. 2,Des 2014 ISSN 1412-6869. 